\title{
LITERATURA E PERFORMANCES POLÍTICAS SOBRE A VIOLÊNCIA CONTRA A MULHER
}

\author{
Carlos Magno Gomes ${ }^{1}$
}

\begin{abstract}
Resumo: A literatura é um importante veículo de divulgação de performances políticas. No caso da autoria feminina brasileira, há diversas obras literárias que questionam a violência contra a mulher por meio de uma estética que parodia e ironiza a masculinidade. Partindo dessas considerações, este artigo apresenta um estudo sobre questionamentos literários acerca da violência de gênero, dando destaque a contos de Lygia Fagundes Telles, Marina Colasanti e Clarice Lispector. Metodologicamente, abordamos os conceitos antropológicos que reconhecem a violência contra a mulher como parte da estrutura hegemônica de manutenção do poder masculino, segundo Rita Laura Segato e Lia Zanotta Machado.
\end{abstract}

Palavras-chave: Estupro. Estudos antropológicos. Violência estrutural.

\section{LITERATURE AND POLICY PERFORMANCES ON VIOLENCE AGAINST WOMEN}

\begin{abstract}
Literature is an important vehicle for the dissemination of political performances. In the case of Brazilian female authorship, there are several literary works that question violence against women through an aesthetic that parodies and ironizes masculinity. Based on these considerations, this article presents a study of literary questions about gender violence in Brazilian short stories, giving prominence to texts of Lygia Fagundes Telles, Marina Colasanti and Clarice Lispector. Methodologically, we approach the anthropological concepts that recognize violence against women as part of the hegemonic structure of maintaining male power, according to Rita Laura Segato and Lia Zanotta Machado.
\end{abstract}

Keywords: Rape. Anthropological studies. Structural violence.

\section{Introdução}

Os estudos antropológicos têm associado a violência de gênero às normas sociais de imposição da masculinidade como um padrão de referência para controle e punição de mulheres. Tal normatização faz parte de mecanismos de controle que insistem em impor uma visão hegemônica da

\footnotetext{
1 Prof. doutor de Teoria Literária (UFS/CNPq), pós-doutorando pelo PPGAS/UnB. Membro do GT da
} Anpoll A mulher na literatura. Editor do periódico Interdisciplinar. Contato: calmag@bol.com.br 
submissão do corpo da mulher ao desejo masculino. Em nossas pesquisas sobre essa violência, na literatura contemporânea brasileira, temos constatado que a paródia e a ironia são usadas pelas escritoras brasileiras para questionarem a violência de gênero, sobretudo o estupro e o feminicídio (GOMES, 2016)². Além disso, defendemos a hipótese de que a masculinidade é deslocada de seu lugar central por meio de performances estéticas de questionamento da violência contra a mulher.

Essa argumentação é fundamentada pelos estudos feministas que reconhecem uma estrutura hegemônica que privilegia a força e a iniciativa do sujeito masculino. Em uma pesquisa sobre a prática do estupro, Lia Zanotta Machado identifica a valorização do "excesso de masculinidade" como uma estratégia de subjugação do corpo da mulher, reassegurando o poder de intimidar ao homem e reafirmando o caráter sacrificável ao corpo da mulher (2010, p. 80). Para Rita Laura Segato (2005), tal violência não é um ato isolado, pois faz parte de regras e normas sociais patriarcais aceitas por grupos que têm interesse em manter seu domínio ideológico hegemônico.

Neste artigo, pretendemos explorar as contribuições antropológicas de questionamento da violência contra a mulher para identificarmos os principais recursos estéticos que deslocam essa violência hegemônica no texto literário. Para isso, dividimos nossa abordagem em dois momentos. No primeiro, retomamos alguns dados acerca da forma como essa violência é percebida no Brasil, tanto pela população brasileira como por escritores e escritoras; e, no segundo, identificamos as peculiaridades estruturais dessa violência denunciadas no conto “A língua do 'P”', da coletânea $A$ via crucis do corpo (1974), de Clarice Lispector. Essa obra expõe a dupla violência que as mulheres sofrem quando denunciam o estupro: a do agressor e da estrutura policial.

Fundamentamos nossos argumentos pela concepção revisionista do texto literário, proposta por Linda Hutcheon, para quem as artistas apresentam uma performance política feminista quando se opõem aos valores universalizantes (1993). Essa interpretação é possível para obras literárias nas quais há uma proposta de revisão da ideologia patriarcal, que questiona o privilégio masculino de apoderar-se "unilateralmente" do corpo

${ }^{2}$ Esta pesquisa é financiada pelo CNPq e abrange o estudo da temática da violência contra a mulher nas narrativas de Clarice Lispector, Lygia Fagundes Telles, Nélida Piñon, Lya Luft, Marina Colasanti e Patrícia Melo e tem resultados parciais publicados nas revistas Scripta, da PUC-Minas, (GOMES, 2016a) e Fórum Identidades, da UFS (GOMES, 2016b). 
da mulher. Rompendo com essa ideologia, as escritoras brasileiras, Lygia Fagundes Telles, Marina Colasanti e Clarice Lispector, entre outras, privilegiam personagens femininas que se deslocam para fora dos espaços opressores. Elódia Xavier ressalta que esse deslocamento ganha destaque nas narrativas produzidas nas últimas décadas do século $\mathrm{XX}$, quando o corpo feminino passa a ser representado como um "corpo liberado", visto que a personagem feminina abandona o sistema disciplinador para viver em liberdade (2007, p. 176).

A seguir, comparamos a concepção que o brasileiro tem acerca da violência de gênero com a forma como essa violência é representada nas obras literárias, dando destaque aos questionamentos das obras de Lygia Fagundes Telles e Marina Colasanti.

\section{A violência no espaço doméstico no Brasil}

A estrutura da violência hegemônica contra as mulheres funciona como forma de controle e de punição e "não são obra de desvios individuais, doentes mentais ou anomalias sociais, mas de expressões de uma estrutura simbólica profunda que organiza nossos atos e nossas fantasias e confere-lhes inteligibilidade" (SEGATO, 2005, p. 270). No Brasil, essa violência é parte da cultura herdada de uma sociedade excludente e extremamente disciplinadora, que impôs a violência como forma de controle e disciplina da mulher desde o discurso religioso, passando pelo controle patriarcal e está presente nos modernos casamentos em que esposas são ameaças por homens que não aceitam o fim de casamentos fracassados.

No contexto familiar brasileiro, a recorrência do cárcere privado e das agressões físicas e morais está centrada em uma contradição social que reconhece a liberdade da mulher ao mesmo tempo em que valoriza o exercício da masculinidade por meio da imposição de punições e castigos. Essa contradição é reconhecida pela população pois, segundo dados do Instituto Patrícia Galvão, 70\% dos brasileiros acreditam que a mulher está mais sujeita à violência em casa (BRASIL, 2014, p. 19). Tal percepção aponta um cenário próximo de países em guerra pelo alto índice de mulheres assassinadas por seus companheiros. Essa violência já é reconhecida como uma epidemia social tanto pelo Estado como pelos brasileiros, conforme 92\% dos entrevistados da 
pesquisa sobre a percepção do brasileiro acerca da violência contra a mulher (BRASIL, 2014, p. 35).

Em pesquisas feitas diretamente com agressores, Lia Zanotta Machado identificou que as justificavas das agressões e dos feminicídios são pautadas pela necessidade de o homem controlar e punir as companheiras e estão relacionadas a valores familiares que foram construídos ao longo de anos, admitindo a extensão do "direito" de posse, advindo do contrato de casamento (2010, p. 79). Esse imaginário da posse e da honra masculina, como motrizes da violência de gênero, também atravessa as justificativas das personagens masculinas agressores da literatura brasileira.

Nas narrativas realistas e regionalistas do século XIX e XX, essa violência é descrita como parte da normatização da moral patriarcal. Nesses casos, a infidelidade imaginária é denunciada pelos escritores como parte da crise da masculinidade, pois há uma relação direta entre "fantasias de identidade" e "fantasias de poder". Nesses casos, a ameaça passa a ser a justificativa para a imposição do controle e da punição, quando "esposas são muitas vezes espancadas por infidelidades imaginárias, o que torna a violência e a ameaça de violência mais eficazes como meio de controle social" (MOORE, 2000, p. 39).

A representação dessa infidelidade imaginária é explorada em diversas obras da literatura brasileira. O clássico Dom Casmurro (1899), de Machado de Assis, traz o debate acerca da "infidelidade imaginária", pois o narrador, Bentinho, descreve uma desconfiança progressiva que se instalou entre ele e sua esposa Capitu, após a morte do amigo Escobar. O ciúme envenena Bentinho, que por sua vez passa a explorar valores morais para punir sua esposa com o assédio psicológico e o exílio em outro país. A esposa é acusada e punida sem direito à defesa. Para o narrador, que passa a desconfiar de tudo após o velório do amigo, não há dúvida, os traços físicos do filho carregam os sinais daquela traição.

A temática da "infidelidade imaginária" é retomada em São Bernardo (1934), de Graciliano Ramos. Nessa obra, o ciúme doentio de Paulo Honório desgasta seu casamento com Madalena, quando o assédio moral e psicológico passa a atormentar a esposa que, para se livrar de um marido tirano, se mata. Apesar de contextos sociais e históricos diferentes, o trágico fim de Madalena é causado por um assédio moral impiedoso, construído a partir do olhar do homem em crise com seus valores morais assim como 
aconteceu com Capitu. Essas duas personagens são exemplos de punição como prática social respaldada no poder masculino de "controlar, fiscalizar a honra e fazer obedecer as mulheres, impondo assim sua vontade quer seja por agressão físico-moral ou apenas moral" (MACHADO, 2017, p. 42).

Em contrapartida, ainda durante o século XX, essa normatização de gênero passou a ser questionada pelos textos de autoria feminina como em $O$ quinze (1930), de Rachel de Queiroz, com uma protagonista que rompe com um namorado, após se recusar a repetir o destino de mulher, o casamento. Conceição não aceita que seu namorado explore sexualmente as moças da fazenda. Sua postura contrária aos valores patriarcais é um marco na luta pelos direitos da mulher. Outra obra que merece destaque por seu pioneirismo da transgressão feminina é Perto do coração selvagem (1944), de Clarice Lispector. Essa obra tanto rompe com a linearidade do romance tradicional, como apresenta a formação de uma jovem que rompe com os papéis tradicionais de menina, moça e mulher obediente para seguir seus caminhos pessoais e subjetivos de seu coração selvagem.

Nos anos 1970, a literatura de autoria feminina passa a registrar com mais frequência episódios de violência de gênero, inserindo nessas representações uma dinâmica estética que questiona os valores sociais que dão sustentação a práticas punitivas. Diversas obras apresentam a reflexão que vai além do campo literário, integrando valores e princípios morais que disciplinam as diferentes formas de castigo e vingança impostos pelo homem traído ou abandonado. Por exemplo, Lygia Fagundes Telles retoma o tema dessa vingança em "Venha ver o pôr do sol", da coletânea Antes do baile verde (1970).

Esse conto ironiza a mente doentia de um rapaz, Ricardo, que não aceita o fim da relação e pede um último encontro com a ex-namorada, Raquel. Ele se diz apaixonado, mas foi humilhado por ter sido trocado por um homem rico, por isso defende apenas o seu ponto de vista: "E eu te amei. E te amo ainda. Percebe a diferença?" (TELLES, 1999, p. 128). Essa postura é muito comum aos agressores e assassinos, que não são guiados por uma regulação de gênero pautada pelo "controle e posse da mulher, desejo de ter, desejo de não perder, desejo de que as mulheres nada queiram a não ser eles mesmos" (MACHADO, 2010, p. 14).

Raquel não percebe que se tratava de um plano de vingança e, mesmo com receio do local, o acompanha até o anunciado túmulo da família.

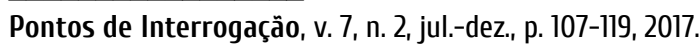


No trajeto, ele vai desqualificando a ex-namorada até o momento que a aprisiona em um jazigo bem afastado da entrada para ela não ter chances de ser ouvida: "Durante algum tempo ele ainda ouviu os gritos que se multiplicaram, semelhantes aos de um animal sendo estraçalhado" (TELLES, 1999, p. 131). Trata-se de um crime premeditado cujo autor é um homem que quer se vingar por ter sido trocado por outro.

Essa vingança é assustadora, mas é respaldada por fazer valer a moral masculina como "moral de macho", daquele que age para valorizar sua virilidade e a força do masculino (MACHADO, 1998, p. 239). Ironicamente, a monstruosidade do jovem vingativo vai sendo tecida pelos detalhes de um crime estrategicamente planejado para ser fatal e não deixar pistas. A ironia que atravessa a postura doentia desse criminoso faz parte de uma concepção literária que artisticamente se projeta como um espaço político de denúncia da violência hegemônica contra a mulher.

Essa mesma performance política é encontrada na coletânea Contos de amor rasgados (1986), de Marina Colasanti, que explora, esteticamente, a paródia como um recurso político ao jogar com imagens de mulheres: compradas, emparedadas e decepadas por homens obsessivos e ciumentos. Especificamente, o conto "Uma questão de educação" apresenta um olhar paródico do feminicídio, ao descrever um homem que decepa a esposa após vê-la conversando com o amante: "Quando ela entrou, decapitou-a com o machado" (COLASANTI, 2010, p. 203). Essa cena traduz uma regra social fundamentada na "incapacidade" de o homem "controlar a vida sexual" de sua esposa. Nesse caso, a violência é uma tentativa de resgatar para si a "administração" de sua masculinidade desmoralizada com a traição (MOORE, 2000, p. 39).

Além da brutalidade deste assassinato, o conto registra a presença do canibalismo, pois o assassino prepara uma sopa da cabeça da esposa morta. Quanto à forma de narrar, o conto é marcado pelo tom irônico e paródico que ressalta o absurdo de valores morais centrados na questão da honra. A contradição entre a brutalidade do assassinato e a rejeição do cabelo na sopa reforça o tom paródico crítico, denunciando o fascismo do feminicídio regulado pela questão de honra: "nunca, desde pequeno criança suportara a visão de cabelos na comida" (COLASANTI, 2010, p. 203).

Assim, a autora traz a tona um riso crítico no final do conto, quando o assassino não consegue tomar a sopa, pois os cabelos da esposa lhe causam 
nojo. Ao não concluir seu ritual canibalista, esse homem se desnuda e expõe a gratuidade de seu assassinato. Tal contradição expõe o quanto o feminicídio é mantido por parâmetros ideológicos que se respaldam na força e na vingança, mesmo quando praticado por homens civilizados, que sabem se portar à mesa. Portanto, da representação de assassinato brutal à delicadeza do marido à mesa, há uma abordagem estética de descentramento da força masculina, denunciando a face perversa dos contratos sociais.

Nos dois contos citados "Venha ver o pôr do sol" e "Uma questão de educação", identificamos diversas reflexões sobre a relação entre personagens femininas e autoras politicamente defensoras dos direitos das mulheres. Esse tipo de narrativa projeta uma performance feminista de revisão que "direta ou indiretamente vincula-se à arte, à moral, à ética e à ideologia" (CAMPELLO, 2006, p. 129). Portanto, a literatura de Lygia Fagundes Telles e de Marina Colasanti traz rastros de um estilo metaficcional que, ideologicamente, destaca a luta pela liberdade feminina. Tal produção literária tem a peculiaridade de deslocar a violência de gênero por meio de uma estética da desregulação de gênero, identificadas pela sátira da fragilidade do assassino.

Essas representações desregulam as normas de gênero, pois retomam representações femininas homogêneas para expor a perversidade das regras sociais. Esse modelo literário é reforçado por descrições irônicas de homens condicionados a repetir apenas as normas de controle e de punição ao seu alcance. Por essa forma de narrar, as personagens agressoras são ridicularizadas por atitudes condizentes com valores morais pautados pela honra masculina. Tal forma de desregulação das normas de gênero é identificada em nossa pesquisa como uma estratégia política de questionamento da violência contra a mulher, visto que o sistema de normatização de gênero tanto apresenta componentes de reprodução dos valores passados como insere modificações nas relações sociais conforme os estudos de Lia Machado (2017, p. 37). Com esse dinamismo, a narrativa de autoria feminina vai além da reprodução temática, pois impõe um ritmo literário de revisão desses valores e reforça uma performance política de denúncia das desigualdades de gênero.

Na continuidade, passamos a identificar regras sociais que culpam a mulher por sofrer abuso sexual. Essa omissão do Estado é pautada por valores estruturais hegemônicos de acordo com o olhar antropológico de Rita Segato 
(2005). Como exemplo, passamos a comentar as formas usadas por Clarice Lispector para denunciar a dupla culpa da mulher assediada.

\section{A dupla punição do corpo feminino}

A violência sexual está entre os crimes que são praticados dentro da lógica de desqualificação do corpo da mulher. Essa violência tem como base de sustentação social uma estrutura de preconceito e exploração da mulher como uma extensão do desejo masculino e é imposta por meio de abusos verbais, físicos e privações. Especificamente, o estupro está relacionado à lógica do "excesso de masculinidade", que é reconhecida pela "dominância de um pensamento que entende a sexualidade polarizada entre uns que são sujeitos e outras que são objetos maculáveis e sacrificiais parece ter os efeitos cruéis" (MACHADO, 1998, p. 250).

Os papéis construídos entre homens e mulheres, no espaço social, levam em conta as subjetividades dessas escolhas, que implicam a forma como os sujeitos se constroem e exercem suas sexualidades. No debate sobre identificações masculinas e femininas, destacamos a questão da flexibilidade e das múltiplas coerências em jogo nessas representações, uma vez que "os indivíduos constituem seu sentido de si mesmos - suas autorrepresentações como sujeitos - por referência a várias posições de sujeito frequentemente contraditórias entre si e não a uma posição singular de sujeito" (MOORE, 2000, p. 23). Assim, a posição do estuprador não é isolada socialmente, pois faz parte de uma dinâmica social, que se mantém pela desqualificação da mulher.

Além dessa estrutura hegemônica de valorização da masculinidade, há diversas formas de julgar e relativizar o abuso sexual contra uma mulher. Em um estudo sobre crimes sexuais e feminicídios não julgados, nem punidos, Rita Laura Segato identificou crimes de corporação para as situações em que a mulher é vítima de diferentes sistemas de governo. Ela parte de um estudo sobre o assassinato e desaparecimento de mulheres no México, em Ciudad Juárez, onde as autoridades não estavam interessadas em punir os culpados, nem a polícia em investigar os crimes praticados por organizações criminosas, apoiadas pela corrupção do Estado (2005).

Nesse contexto, a mulher é vítima por ser mulher, visto que as agressões sexuais e físicas são praticadas contra a mulher como uma 
categoria e não a um sujeito específico, já que é despersonalizada “como sujeito porque se faz predominar nele a categoria à qual pertence sobre suas características individuais biográficas ou de personalidade" (SEGATO, 2005, p. 279). No Brasil, essa forma de violência que despersonaliza a mulher é comum também aos crimes de estupros praticados por estranhos. Nesses casos, a violência contra a mulher é praticada por ela ser mulher, por andar em lugares ermos e/ou por andar de forma "provocante". Essa prática de culpabilizar a mulher por ter sofrido estupro ainda é muito comum no Brasil do século XXI, mesmo com diversas manifestações feministas públicas e nas redes sociais contra esse comportamento das autoridades brasileiras.

Para ilustrar a dinâmica da violência estrutural hegemônica, passemos a comentar como Clarice Lispector, em "A língua do P", desloca as engrenagens da punição e do sacrifício feminino, ao explorar a estrutura simbólica do abuso do corpo da mulher por meio de um texto irônico e mordaz, que questiona a culpabilização das vítimas de estupro ${ }^{3}$. As perversas formas dessa padronização são debatidas quando uma passageira, Cidinha, se disfarça de prostituta para escapar de um estupro. Ela aparentemente era "nem rica nem pobre: remediada. Mas vestia-se com apuro. Parecia rica. Até sua malas eram de boa qualidade" (LISPECTOR, 1998, p. 67). Ao representar uma mulher ameaçada pela violência, esse conto expõe valores que dão sustentação à estrutura de punição da mulher.

No decorrer da viagem entre Minas e Rio de Janeiro, o assédio sexual se dá quando Cidinha passa a decodificar a linguagem usada por dois desconhecidos que planejavam: "currá-la no túnel" (LISPECTOR, 1998, p. 68). Nesse caso, o estupro tem a finalidade de posse e apropriação do corpo da mulher como um território somente por ser um corpo feminino e é guiado pela lógica masculina arbitrária de aniquilamento de sua vítima.

Ao saber que seria violentada, Cidinha toma consciência do desejo masculino que, não satisfeito com a possibilidade de violação do seu corpo, passa a usar o terror do assassinato como forma de controle: "Se resistisse podiam matá-la" (LISPECTOR, 1998, p. 68). Sem poder contar com a ajuda dos usuários do trem, por ser ameaçada de morte, Cidinha passa a se comportar como uma mulher vulgar: "abriu os botões do decote, deixou os seios à mostra" (LISPECTOR, 1998, p. 69), passando a se fingir de prostituta. A

\footnotetext{
${ }^{3}$ Uma versão que analisa as particularidades do feminicídio, presentes neste conto de Lispector, foi
} publicada na revista Estudos Feministas (GOMES, 2014).

Pontos de Interrogaçăo, v. 7, n. 2, jul.-dez., p. 107-119, 2017. 
mudança de comportamento passa a ser sua única estratégia para escapar da violação arbitrária a que estava exposta.

Quanto à forma de narrar, essa abrupta mudança de comportamento pode ser entendida como uma crítica à violência estrutural, pois Cidinha significava a "transgressão do interdito" e era a vítima ideal. No entanto, eles perdem o interesse por ela ao identificarem a falta de resistência e sua mudança de comportamento. O desejo de violentar um corpo venerado por seu comportamento social também reforça o quanto essa estrutura de violência é composta por uma rede de valores contraditórios que vão da valorização do corpo feminino puro e limpo, mas é desprezado e aniquilado se considerado violado e sujo (SEGATO, 2003, p. 5-6). O corpo de Cidinha deixou de ser assediado por ter transitado do puro ao sujo.

Ao jogar com papéis femininos trocados: a mulher "idealizada" pela "disponível", Lispector brinca com a estrutura de gênero que tende a punir sempre. Nesse caso, a literatura descentra as fantasias sexuais masculinas que reforçam o culto à violação do corpo da mulher virgem/comportada como um triunfo da masculinidade. No texto, a autora vai além desse jogo e passa a descrever a segunda via crucis de a mulher ser ouvida pelas autoridades policiais, quando Cidinha é denunciada ao maquinista, que não tem dúvidas quanto a sua culpa: "vou entregar ela pra polícia na primeira estação" (LISPECTOR, 1998, p. 69).

Depois de expulsa do trem, ela passa três dias presa: "Foi levada ao xadrez e lá fichada. Chamaram-na dos piores nomes" (LISPECTOR, 1998, p. 6970). Com essa punição, o texto de Clarice extrapola os sentidos sexuais ao descrever uma mulher que denuncia a agressão sexual e é considerada culpada por seu comportamento. A falta de punição dos culpados aproxima-se do que constatou Rita Segato sobre a violência estrutural hegemônica: os homens estão mais preocupados em proteger seu nicho de masculinidade quando participam do poder e formam "um grupo ou rede que administra os recursos, direitos e deveres próprios de um Estado" (2005, p. 283). Os personagens masculinos desse conto agem de acordo com uma estrutura de valores que desqualifica o corpo da mulher para mantê-la sempre sobre vigilância e sem direitos.

Esteticamente, o conto questiona uma estrutura social hegemônica que privilegia a masculinidade por meio da ironia e dos deslocamentos ideológicos, que expõem a desigualdade de gênero. Essa argumentação pode 
ser mantida por se tratar de um texto que vai além de ficcionalizar da violência, pois revela as faces perversas do silenciamento da mulher. Nesses casos, percebemos que "a ficção se constrói labirinticamente em busca do Outro, exibe seus artifícios e inscreve a diferença nas suas escolhas formais" (OLIVIERI-GODET, 2007, p. 234). Ao descentrar o lugar masculino, parodiando uma estrutura omissa que pune a vítima, Lispector pode ser apontada como uma das escritoras contemporâneas preocupadas em denunciar as diferentes formas estruturais de violência contra a mulher.

\section{Considerações finais}

No campo social, os desafios ainda são inúmeros, pois infelizmente, os índices de violência são apontados por $56 \%$ da população que conhece alguma mulher que já sofreu violência (BRASIL, 2014, p. 56). Essa situação é agravada por uma concepção jurídica que considera esses crimes como delitos de menor importância, já que fazem parte da esfera doméstica. Para alguns juristas, o Estado não pode legislar nessa esfera, argumentando que, no espaço da casa, deve prevalecer a harmonia familiar, "transformando os conflitos e violências de gênero como bagatelas” (MACHADO, 2017, p. 44).

Como visto neste artigo, a violência é um fantasma que faz parte de práticas ancestrais de controle da mulher e que insistem em assombrar a modernidade. Como fantasma, ela não tem face, mas está presente tanto nas estatísticas e nos dados sobre a violência no Brasil como também é representada nos textos literários. Machado e Ramos, em Dom Casmurro e São Bernardo, respectivamente, descrevem homens doentes de ciúmes que controlam suas esposas. Já Telles e Colasanti, nos contos "Venha ver o pôr do sol" e "Uma questão de educação" optam por desnudar a estrutura social que dá sustentação à questão da honra masculina, respaldando as agressões e o assassinato. A proposta literária dessas duas autoras expõe a face doentia desses assassinos.

Com o questionamento do assédio sexual, que culpabiliza a mulher, o texto de Lispector é pioneiro por expor de forma sucinta a estrutura moral que relativiza a violência contra a mulher. Seu conto "A língua do P" projeta essa sociedade que pune duplamente a mulher: por andar só e por se vestir e se comportar como quiser. Essa postura política crítica pode ser identificada 
na forma como a mulher é expulsa do trem, enquanto fugia de estupradores, por desrespeito aos bons costumes sociais. Tal performance estética também pode ser identificada pela ironia que atravessa o texto, desnudando as estratégias de culpabilização da mulher. Tal tipo de ficção "inscreve a diferença nas suas escolhas formais, transformando o escritor em personagem, multiplicando os níveis narrativos e os pontos de vista" (OLIVIERI-GODET, 2007, p. 234).

Em particular, a ficção de autoria feminina pode ser explorada como uma estratégia de conscientização a favor da mudança de paradigmas culturais que libertem as mulheres desses crimes herdados de um sistema disciplinador e punitivo. Se pensarmos nos textos literários citados no decorrer deste artigo, podemos deduzir que Lygia Fagundes Telles, Marina Colasanti e Clarice Lispector são três escritoras que produziram uma literatura marcada pela performance política de luta pela igualdade de gênero. Explorar esse potencial questionador da literatura é fundamental para fortalecermos uma crítica cultual que revise os sentidos de práticas ancestrais fundamentadas pela desigualdade de gênero.

\section{Referências}

BRASIL. Pesquisa sobre a Percepção da sociedade sobre violência $e$ assassinato de mulheres. São Paulo: Data Popular e Instituto Patrícia Galvão, 2014.

CAMPELLO, Eliane. O Künstlerroman de autoria feminina no Brasil. In: Cavalcanti, Ildney et al. (Org.). Da mulher às mulheres. dialogando sobre literatura, gênero e identidades. Maceió: Edufal. 2006. p. 125-133.

COLASANTI, Marina. Marina. "Uma questão de honra". In: COLASANTI, Marina. Marina. Contos de amor rasgados. 3. edição. Rio de Janeiro: Record, 2010.

GOMES, Carlos Magno. O femicídio na ficção de autoria feminina brasileira. Estudos Feministas. Florianópolis, UFSC, v. 22, n. 3, p. 781-794, 2014.

GOMES, Carlos Magno. Intertextos e mediações culturais em Nélida Piñon. Scripta, Belo Horizonte, PUC, v. 20, n. 39, p. 277-290, 2016 a.

GOMES, Carlos Magno. A violência de gênero e a crise de masculinidade. Revista Fórum Identidade, Itabaiana, UFS, v. 21, p. 33-48, $2016 \mathrm{~b}$. 
HUTCHEON, Linda. La política de la parodia postmoderna. Traducción del inglés por Desiderio Navarro. Revista Criterios. La Habana, edición especial, p. 187-203, 1993.

LISPECTOR, Clarice. "A língua do p". In LISPECTOR, Clarice. A via crucis do corpo. Rio de Janeiro: Rocco, 1998.

MACHADO, Lia Zanotta. Masculinidade, sexualidade e estupro. Cadernos Pagu. Campinas, v. 11, p. 231-73, 1998.

MACHADO, Lia Zanotta. Feminismo em movimento. 2. edição. São Paulo: Francis, 2010.

MACHADO, Lia Zanotta. Violência contra as mulheres: diálogos entre feminismo e ciência social. In DIAS, Alfrancio et al.(orgs) $A$ transversalidade de gênero na produção do conhecimento e nas políticas públicas. Aracaju: Editora IFS, 2017. p. 37-54.

MOORE, Henrietta. Fantasias de poder e fantasias de identidade: gênero, raça e violência". Cadernos Pagu, Campinas, v. 14, p. 13-44, 2000.

OLIVIERI-GODET, Rita. "Estranhos estrangeiros: poética da alteridade na narrativa contemporânea brasileira". Estudos de literatura brasileira contemporânea. Brasília, n. 29, p. 233-252, 2007.

SEGATO, Rita Laura. Las estructuras elementales de la violencia: contrato y status en la etiología de la violencia. Série Antropológica. Brasília: Departamento de Antropologia da UnB, 2003.

SEGATO, Rita Laura. "Território, soberania e crimes de segundo Estado: a escritura nos corpos das mulheres de Ciudad Juarez". Estudos Feministas. Florianópolis, v. 13, n. 2, p. 265-285, 2005.

TELLES, Lygia Fagundes. Venha ver o pôr do sol. In: TELLES, Lygia Fagundes. Antes do baile verde. 16. edição. Rio de Janeiro: Rocco, 1999, p. 123-131.

XAVIER, Elódia. Que corpo é esse? O corpo no imaginário feminino. Santa Catarina: Mulheres, 2007.

Recebido em: 01/11/2017

Aprovado em: 30/11/2017 